\title{
Laboreal
}

Volume $16 \mathrm{~N}^{\circ} 1 \mid 2020$

Quando o trabalho real é tabu

\section{Pilotando a experiência : o mapeamento das competências baseado na análise da atividade do Projeto BAJA}

Conduciendo la experiencia : mapeo de competencias basado en el análisis de actividad del proyecto BAJA

Conduire l'expérience : cartographie des compétences basée sur l'analyse des activités du projet BAJA

Conducting the experience : Competency Mapping Based on BAJA Project

Activity Analysis

Rodrigo Augusto dos Santos e Raoni Rocha

\section{OpenEdition}

\section{Journals}

Edição electrónica

URL: http://journals.openedition.org/laboreal/16031

DOI: 10.4000/laboreal.16031

ISSN: 1646-5237

Editora

Universidade do Porto

Refêrencia eletrónica

Rodrigo Augusto dos Santos e Raoni Rocha, « Pilotando a experiência : o mapeamento das competências baseado na análise da atividade do Projeto BAJA », Laboreal [Online], Volume 16 NN1 $^{0}$ 2020, posto online no dia 01 julho 2020, consultado o 09 julho 2020. URL : http:// journals.openedition.org/laboreal/16031; DOI : https://doi.org/10.4000/laboreal.16031

Este documento foi criado de forma automática no dia 9 julho 2020

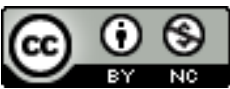

Laboreal está licenciado com uma Licença Creative Commons - Atribuição-NãoComercial 4.0 Internacional. 


\section{Pilotando a experiência : o mapeamento das competências baseado na análise da atividade do Projeto BAJA}

Conduciendo la experiencia : mapeo de competencias basado en el análisis de actividad del proyecto BAJA

Conduire l'expérience : cartographie des compétences basée sur l'analyse des activités du projet BAJA

Conducting the experience : Competency Mapping Based on BAJA Project

Activity Analysis

Rodrigo Augusto dos Santos e Raoni Rocha

\section{NOTA DO EDITOR}

Manuscrito recebido em / Manuscrito recibido en : 21/01/2020

Aceite após peritagem / Aceptado tras peritaje : 02/06/2020

\section{Introdução}

O programa Baja SAE BRASIL é uma competição nacional para estudantes de engenharia de universidades de todo o Brasil, que propicia a oportunidade de aplicar conhecimentos adquiridos em sala de aula ao envolver os alunos em casos reais de concepção, construção e testes de um veículo off road (SAE BRASIL, 2019). O projeto também é desenvolvido na Universidade Federal de Itajubá, no campus da cidade de Itabira, através da equipe "MountainBaja", com a participação de alunos das diversas 
áreas da engenharia, dividida em setores que trabalham os processos do projeto e da construção do automóvel.

O projeto BAJA expõe os estudantes aos desafios encontrados no desenvolvimento do veículo, estimulando a criatividade para a solução de problemas em um cenário onde a competência faz dos alunos profissionais criativos e disputados no mercado (Ferreira \& Caporalli Filho, 2013). As atividades de extensão universitária propiciam contribuições à formação do estudante, permitindo o desenvolvimento da experiência discente em termos teóricos e metodológicos (Fórum de Pró-Reitores de Extensão das Universidades Públicas Brasileiras, 2001), colocando o aluno como protagonista de sua formação técnica para a aquisição de competências necessárias à atuação profissional (Fórum de Pró-Reitores de Extensão das Universidades Públicas Brasileiras, 2007).

3 A MountainBaja participa anualmente das competições Baja SAE BRASIL e da Regional Etapa Sudeste. Embora com avanços em seus resultados nos torneios, a equipe lida com problemas relacionados à transmissão do conhecimento que, segundo Faurie et al. (2013), se trata tanto de um processo dinâmico mediante ao que se produz, transmite e mobiliza de conhecimentos, quanto de um produto, em referência às ferramentas de transferência do conhecimento. Um dos problemas relacionados à transmissão do conhecimento no projeto é a alta rotatividade dos membros da equipe que, composta exclusivamente por alunos da Universidade, está sempre sujeita a alterações em sua composição no decorrer do projeto.

4 A realidade da alta rotatividade dos membros da equipe pode gerar sobrecarga de trabalho aos integrantes que continuam no projeto, além da redução de produtividade e atrasos no cronograma (Frufrek \& Pansanato, 2017). O membro que vai embora leva consigo a própria experiência ou o conhecimento tácito, resultado da sua prática de trabalho, podendo ainda significar perda significativa da memória organizacional (Ress, Moraes, \& Nakano, 2010).

5 A gestão do conhecimento implica que o conhecimento tácito seja o início da mensuração da eficiência das organizações, inovação e tomada de decisões com relação às melhores estratégias, mapeando e reconhecendo os dados, informações e conhecimentos estruturados (Runte, 2011).

6 A demanda da pesquisa partiu do coordenador do projeto BAJA em decorrência da alta rotatividade. $O$ estudo realizado na MoutainBaja ocorreu em um contexto de pesquisa de iniciação científica. $O$ objetivo é, a partir de uma compreensão profunda do trabalho desenvolvido na equipe, amparado nas bases da Ergonomia da Atividade (Falzon, 2007 ; Guérin et al., 2001), realizar um mapeamento da experiência dos integrantes para propor condições de dinamizar a transferência de conhecimento em todos os setores que compõe as fases de produção do veículo, fazendo uso do conceito de "Níveis de Similaridade" (Ribeiro, 2013), que qualifica a experiência dos agentes, estima e gere o conhecimento tácito associado aos indivíduos que fazem parte do projeto.

\section{Referêncial Teórico}

\subsection{A não retenção do conhecimento no projeto BAJA}

7 O Programa Baja SAE (Society of Automotive Engineers) foi criado nos Estados Unidos, tendo sua primeira edição em 1976. Em 1991 começaram as atividades no Brasil e em 
1995 foi realizada a primeira competição nacional. Os estudantes que participam do Programa representam, nas competições, a Instituição de Ensino Superior da qual fazem parte, trabalhando em equipe em todas as fases do projeto de um veículo fora de estrada. A equipe vencedora ganha o direito de competir a etapa internacional nos Estados Unidos (SAE Brasil, 2019).

De acordo com o Regulamento Administrativo e Técnico do Baja SAE BRASIL (SAE Brasil, 2019), o desempenho da equipe será avaliado pelo sucesso nas competições, devendo ser um protótipo para produção em série e, ao mesmo tempo, ser de fácil manutenção, ergonômico e econômico, atendendo ao mercado consumidor, buscando desempenho líder de mercado em velocidade, manobrabilidade, conforto e robustez em terreno acidentado. Cada projeto tem duração de um ano, período entre os calendários de competições. Não existem prescrições específicas quanto à participação do aluno em projetos distintos ao longo do tempo.

9 A instituição de ensino deve designar um professor orientador que irá representar a equipe na competição. $O$ professor deve auxiliar os alunos através das teorias aplicadas ao projeto, porém sem envolvimento direto no desenvolvimento do veículo ou na preparação de relatórios, fabricação de peças, montagem do veículo, manutenção e testes (SAE Brasil, 2019). Na equipe MountainBaja, o professor orientador é o mesmo desde a fundação da equipe.

Devido a não exclusividade dos membros da equipe para o projeto, frequentemente as atividades não são cumpridas nos prazos estabelecidos, gerando atrasos e comprometendo o desempenho das atividades finais (Linares, Sartor, Oliveira, Cabral, \& Assis, 2013). Normalmente, um grande número de participantes se retira do projeto ao longo do ano por ser uma ocupação que demanda dedicação, principalmente aos finais de semana e férias (Ribeiro, 2015).

11 Reter o conhecimento na equipe, evitando repetir erros do passado, é preocupação de todas as equipes Baja SAE, mas que, na prática, acabam ficando sujeita à rotatividade de seus integrantes (Ferreira \& Caporalli Filho, 2013), ou seja, à "substituição do ocupante de um posto de trabalho por outro" (Departamento Intersindical de Estatística e Estudos Socioeconômicos, 2011, p.11). Este fato prejudica o processo de difusão do conhecimento nas equipes (Lima, 2018).

12 A rotatividade de pessoal é um problema para muitas organizações em função da queda da produtividade até a perda de historicidade da instituição, que parece também demitida com os veteranos que partem (Ferreira \& Freire, 2001), acarretando prejuízos estratégicos dependendo das informações que o profissional pode levar para os concorrentes (Silva, Cappellozza, \& Costa, 2014).

\subsection{Gestão do conhecimento tácito através dos "Níveis de similaridade"}

13 O conhecimento explícito é aquele capaz de ser apresentado em palavras ou números e compartilhado na forma de dados, fórmulas científicas, recursos visuais, registros manuais ou de áudio. Trata-se do tipo de conhecimento mais comum que encontramos nas empresas, uma vez que é traduzido através das regras e portais de informação (Collins, 2010). Já o conhecimento tácito contém uma importante dimensão incorporada composta por crenças, perceções, valores, emoções e modelos mentais (Takeuchi \& 
Nonaka, 2008), sendo, portanto difícil de ser verbalizado. O conhecimento tácito não é traduzido em regras explícitas. Ao contrário disso, é aprendido ao longo de períodos de experiência e de execução de uma atividade, durante as quais o indivíduo desenvolve uma capacidade para fazer julgamentos intuitivos sobre a realização bem-sucedida da atividade (Ribeiro, 2013). Conhecimento tácito, portanto, pode ser traduzido por "experiência" sendo, dessa maneira, vital para as organizações porque as empresas só podem aprender e inovar se estimularem o desenvolvimento deste tipo de conhecimento entre seus membros (Choo, 2003).

Para se falar em conhecimento tácito é necessário que se conheça os limites reais da experiência em questão. Já que o conhecimento tácito é incorporado e adquirido através da experiência, não é possível ter conhecimento tácito em muitas situações distintas (Collins, 2010). Em outras palavras, este conhecimento deve ser qualificado, ou determinado sobre qual situação e durante quanto tempo essa experiência existe. Neste sentido, Ribeiro (2013) defende que :

“(...) não é suficiente dizer, por exemplo, que alguém tem 20 anos de experiência em manutenção. Há tantas 'experiências em manutenção' quanto há áreas de manutenção (manutenção elétrica e mecânica, engenharia civil, automação e instrumentação), tipos de manutenção (manutenção corretiva, preventiva e preditiva), papéis na manutenção (e.g. inspetor, eletricista, mecânico, vulcanizador, planejador, etc.), tipos de equipamento e marcas distintas (que fazem diferença, às vezes), variações na capacidade e complexidade dos equipamentos (e.g., nível de automação), maneiras diferentes de organizar a manutenção (manutenção departamental ou centralizada) e daí por diante. Por isso, é impossível qualificar a experiência baseando-se em cada um dos detalhes do trabalho de alguém - se fosse assim, haveria apenas uma única experiência para cada indivíduo" (pp. 346-347, tradução livre).

Assim, para qualificar a experiência, de maneira a mensurar e classificar o conhecimento tácito incorporado às práticas, Ribeiro (2013) desenvolve o conceito de "Níveis de Similaridade", que leva em consideração as situações vividas pelos trabalhadores e suas habilidades em interpretar e aplicar uma regra, assim como avaliação das consequências de ações ou de eventos em curso. A ideia principal do autor é compreender como podemos identificar e estimar o conhecimento tácito dos trabalhadores ou como podemos planejar atividades de intercâmbio entre indivíduos com diferentes níveis de experiência a fim de desenvolver projetos sustentáveis nas empresas.

Neste sentido, identificar "Níveis de Similaridade" entre as atividades e as situações permite comparar o quão similar o local e a experiência prévia de trabalho são da função que o trabalhador deve desempenhar no futuro, e identificar que, quanto maior a similaridade entre as atividades e situações, mais perto se está da experiência necessária para a função estudada, permitindo assim investir na formação de profissionais ou na contratação de pessoas para as áreas de conhecimento frágil ou inexistente.

\subsection{A Ergonomia da Atividade como base para a gestão do conhecimento tácito}

17 Toda pesquisa que busca a compreensão do trabalho real executado no campo, encontra na Ergonomia da Atividade métodos e ferramentas capazes de contribuir de maneira significativa com o cumprimento desse objetivo, uma vez que se trata de uma 
disciplina que estuda a atividade real executada pelos trabalhadores, a fim de propor transformações práticas que garantam uma produção condicionada à preservação da saúde dos indivíduos e da segurança do sistema sociotécnico (Falzon, 2007).

A análise da atividade apresenta aspectos de trabalho frequentemente desconhecidos, tornando visível a diversidade das atividades dos sujeitos para cumprir as expectativas da gestão da produção, através de regulações, escolha de informações pertinentes, antecipação e raciocínios oportunos a cada momento, diante de cada evento inesperado (Guérin et al., 2001). Para a Ergonomia, a atividade corresponde ao que os trabalhadores fazem e como cada sujeito usa de si para realizar aquilo que foi - e também não foi previsto nas tarefas para se alcançar os resultados desejados de produção (Sznelwar, 2009). Para isso, os trabalhadores encontram modos de fazer próprios e específicos à situação na qual estão inseridos, para prever e corrigir as disfunções do sistema. Em outras palavras, eles buscam regulações, individuais e coletivas, locais e sistêmicas, para que os objetivos de produção sejam atingidos com eficiência e segurança (Rocha, 2017).

Ora, para colocar em prática todo esse conjunto de ações face aos imprevistos da situação real, é necessário que os indivíduos adquiram experiência. Ao mesmo tempo, os indivíduos com mais experiência são aqueles com maior capacidade de desenvolver estratégias e regulações para enfrentar os eventos não previstos das situações de trabalho (Delgoulet \& Vidal-Gomel, 2013). É através da prática que os operadores obtêm experiência e tornam-se competentes, desenvolvendo habilidades potencialmente capazes de resolver determinado tipo de problema, dominar certos recursos ou mobilizar novos saberes (Delgoulet, 2015; Stroobants, 2006). Entre esses novos conhecimentos, eles desenvolvem regulações que possibilitam ao operador experiente agir de forma diferente e fazer uso de ações mais eficazes e menos exigentes em termos de esforço em relação ao operador novato (Falzon \& Mollo, 2009). O conhecimento está, portanto, implícito em nas ações (Granovsky \& Poy, 2012). É por meio da atividade real desenvolvida no trabalho que a experiência individual e coletiva se produz. Um sujeito adquire experiência quando aprende, desenvolve competências, se socializa em um grupo ou torna-se hábil para agir à sua maneira singular, orientado por normas e valores em um contexto (Mata, Oliveira, \& Barros, 2017).

Conhecer a experiência do indivíduo ou dos coletivos de trabalho implica, necessariamente, em conhecer a atividade que eles desempenham. Isso é possível por meio da Ergonomia da Atividade, disciplina que possibilita a transformação do trabalho real através de um profundo conhecimento da atividade realizada. Essa relação entre atividade e experiência é reforçada a partir do momento em que a Ergonomia da Atividade, enquanto disciplina científica, também reivindica que o seu objetivo é o desenvolvimento dos indivíduos - através de situações que favoreçam a aquisição de competências - e o desenvolvimento das organizações - através da construção de processos reflexivos e, consequentemente, de aprendizagem no interior delas mesmas (Falzon, 2016 ; Rocha, Mollo, \& Daniellou, 2019).

\section{Descrição das Atividades Desenvolvidas}

21 A metodologia usada nesse estudo foi embasada na Análise Ergonômica do Trabalho (AET) (Guérin et al., 2001), seguindo as grandes etapas da AET, quais sejam : análise da demanda, análise da tarefa e da atividade e observações abertas nos 15 setores do 
projeto. No entanto, não houve rigor na aplicação das ferramentas em cada etapa devido ao contexto de um projeto universitário no qual muitas atividades são realizadas em reuniões remotas ou ao acaso de horários livres entre os participantes. Junto a isso, o objetivo maior da aplicação da AET foi compreender o trabalho dos indivíduos, e não necessariamente estabelecer um diagnóstico ergonômico nos moldes de uma AET clássica. Como ressaltam Guérin et al. (2001), a abordagem da AET não deve ser entendida como uma série de métodos a aplicar um após o outro, mas sim, como um método passível de ajustes em função do contexto organizacional.

A demanda da pesquisa foi proposta pelo coordenador do projeto BAJA da UNIFEI campus Itabira em virtude da alta rotatividade dos membros do projeto. $O$ fato de ser um membro externo levou o pesquisador a desenvolver uma intensa articulação através de discussões, trocas de mensagens e e-mails com as lideranças e os demais participantes - na programação de entrevistas e visitas técnicas. O pesquisador precisou passar horas junto à equipe para compreender seu funcionamento, coletando informações em observações abertas, avançando ao longo de hipóteses que surgiam e colocando-as em confrontação com a perceção dos indivíduos.

O trabalho de coleta de dados em campo foi efetivado em nove meses, num total de 72 horas, por meio de 35 entrevistas semiestruturadas e de autoconfrontação com componentes ativos e não ativos da equipe; visitas a seis dias de montagem do carro durante duas semanas de preparação para a competição; visitas intermitentes na oficina; 36 reuniões setoriais, além de duas reuniões gerais realizadas ao longo da temporada.

Essa pesquisa foi dividida em duas fases. Na primeira, foram efetuadas análise de documentos do projeto, entrevistas com todos os participantes e observação da atividade com o objetivo de compreender o processo técnico e as tarefas da equipe, observando as estratégias adotadas por eles. $\mathrm{Na}$ fase seguinte, foram realizados dois workshops específicos com o intuito de mapear as competências e, dessa forma, identificar as carências em cada um dos setores do projeto BAJA para propor alternativas de contratação específicas para o projeto. Cada uma dessas duas fases será detalhada abaixo.

\subsection{Compreensão do trabalho da equipe}

Foi realizada uma análise para compreensão do funcionamento da equipe. Os procedimentos utilizados foram os seguintes :

a. Análise documental, ou seja, de materiais que ainda não receberam tratamento analítico ou que ainda podem ser reelaborados de acordo com os objetivos da pesquisa (Gil, 2008). Assim, foi estudado o regulamento da competição do SAE BRASIL, com o objetivo de identificar informações relativas ao processo de construção do veículo, bem como da competição em si.

b. Observação aberta da atividade real dos membros da equipe, buscando um contato pessoal e estreito do pesquisador com o fenômeno pesquisado (Lüdke \& André, 1986). As observações foram realizadas mediante visitas à oficina de construção do veículo para acompanhar o trabalho real e a preparação para a competição.

c. Entrevistas semiestruturadas, que partem de questionamentos básicos e oferecem amplo campo de interrogativas em consequência de novas hipóteses que surgem em função das respostas (Triviños, 1987). As entrevistas foram feitas baseadas num roteiro com 10 perguntas, contemplando a identificação do perfil profissional do entrevistado, tempo de 
equipe, suas responsabilidades, atividade que realiza e necessidades em termos de competências para a realização da sua atividade.

\subsection{Gestão do Conhecimento}

26 determinassem uma composição efetiva para cada um dos setores por meio de um mix de similaridade. $O$ propósito foi pensar em uma composição efetiva para cada um dos setores que permitisse a construção de um projeto final eficaz e expandisse a quantidade do conhecimento tácito efetivo. A configuração desejada para os setores em relação às competências foi expressa em uma tabela com os níveis de similaridade atuais e os pretendidos para a captação de novos membros.

\section{Resultados e Discussão}

\subsection{Contextualização do campo}

30 Foi elaborado um organograma para a compreensão da estrutura formal da equipe, os cargos existentes, a quantidade de pessoas por unidade, a relação funcional e hierárquica. Também são apresentadas verbalizações que demonstram ausência de registro formal na equipe, a não retenção da experiência e as consequências disso, como a redução do tempo de prática do piloto ao carro. Por fim, é mostrado que 
tentativas de gestão de conhecimento são realizadas de forma esporádica e informal na equipe.

\subsubsection{Estrutura e Funcionamento da Equipe}

Os setores que compõe a equipe são os seguintes: Marketing e Patrocínio ; Gestão de Projetos ; Gestão de Pessoas ; Cálculo Estrutural ; Direção e Suspensão ; Elétrica ; Design e Acabamento; Transmissão; Freio; Ergonomia; Administrativo e Financeiro; e Materiais e Suprimen133tos. Também foram estudadas as funções de piloto e capitão (cargo análogo a gerente da equipe).

Foi elaborado o organograma da equipe para o entendimento da estrutura organizacional, compreendendo a maneira como as atividades do projeto estão divididas. A estrutura organizacional pode ser entendida como a representação dos níveis hierárquicos e a divisão do trabalho no interior das organizações (Schultz, 2016) e o organograma, a "fotografia" da hierarquia e da divisão de atividades da organização (Balcão, 1965). 0 organograma da equipe pode ser compreendido na Figura 1.

\section{Estrutura organizacional da Equipe MountainBaja}

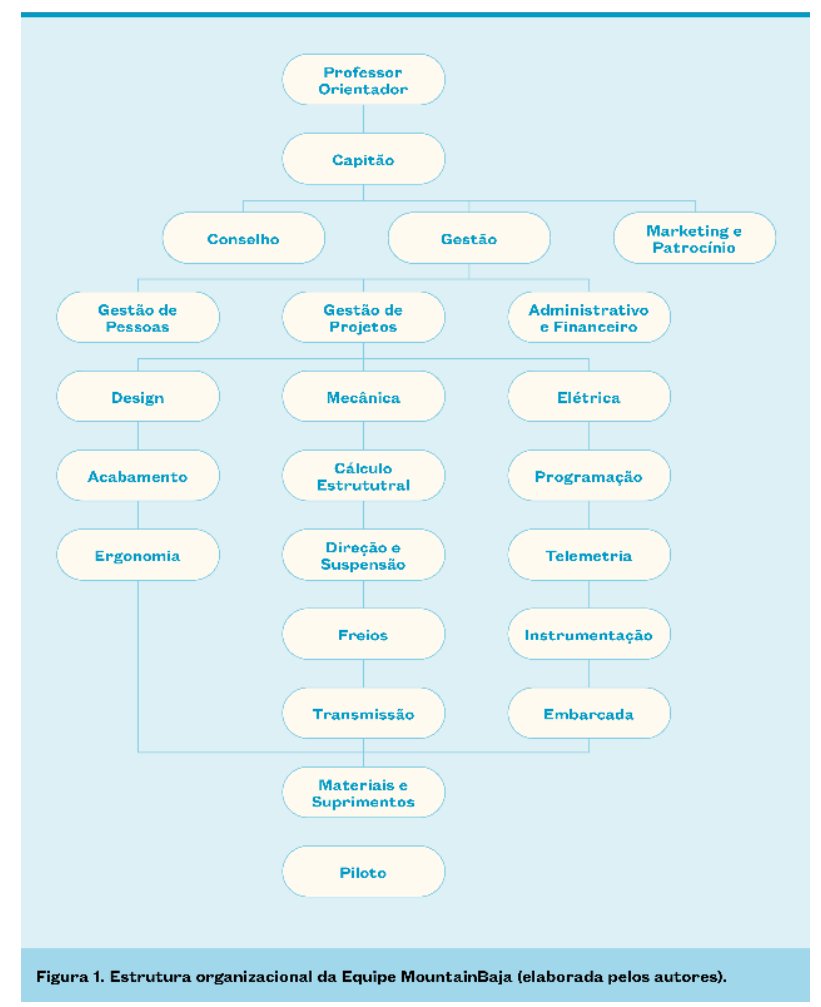

FIgURA 1. Estrutura organizacional da Equipe MountainBaja (elaborada pelos autores)

Embora não haja registros formais sobre o tema na equipe, pode-se perceber que a rotatividade dos indivíduos, durante o período de pesquisa, foi alta. Numa análise feita nos 18 meses de contato entre pesquisador e a equipe, observou-se que, dos 22 membros iniciais, 12 deixaram a equipe e outros 22 ingressaram, havendo também alteração do capitão da equipe.

A admissão na MountainBaja é por processo seletivo dividido em cinco etapas: inscrição; prova sobre o Regulamento Administrativo e Técnico Baja SAE BRASIL; 
dinâmica de grupo ; entrevista ; e processo trainee. Essa última etapa é dividida em duas fases. Na primeira, há uma aula intensiva sobre os setores com duração de 30 minutos cada. Na segunda fase, o candidato desenvolve projetos relativos ao setor que serão avaliados pela equipe. Ao fim desse processo, são selecionados os postulantes com o perfil desejado.

Na competição, o automóvel participa de eventos dinâmicos, destinados a avaliar o funcionamento dos veículos em variedade de condições. Além das provas realizadas pelo veículo, cada setor da equipe precisa exibir os resultados obtidos na construção do carro de acordo com as solicitações requeridas no regulamento, por meio de apresentações e relatório de projetos contendo as considerações de engenharia e os processos utilizados no desenvolvimento de cada sistema.

\subsubsection{Dificuldades e Regulações}

É comum que o início do aprendizado de novas habilidades seja por meio de instruções escritas ou verbais, onde o novato pode aprender a identificar vários fatores relevantes à habilidade, adquirindo regras para determinadas ações (Dreyfus, 2001/2009; Dreyfus \& Dreyfus, 2012). Assim a codificação do conhecimento explícito favorece a rápida recuperação quando preciso (Tonet \& Paz, 2006).

Entretanto, não há na MoutainBaja registro formal das atividades desenvolvidas em projetos anteriores ou prescrições das funções. Para a aquisição de conhecimento teórico, os participantes fazem as suas próprias pesquisas.

"A maior dificuldade mesmo foi de não ter nada escrito. Se eu for pegar pra fazer um material agora, um chapéu (de carenagem), eu não vou ter a proporção da resina, qual resina foi usada. Eu tenho de começar do zero tudo o que eu vou fazer" (Membro do setor de Design e Acabamento)

"Quando entramos na Transmissão, pegamos o setor desestruturado, pois não havia integrantes no setor, eles tinham acabado de sair. Então nossa maior dificuldade foi aprender as coisas mesmo do setor, porque é muito diferente uma transmissão de um Baja para um veículo convencional" (Membro do setor de Transmissão)

38 A ausência de registro pode prejudicar a formação da memória da equipe, que é o conjunto de conhecimentos explícitos e tácitos incorporados e retidos pela organização ao longo de sua existência, utilizados para o suporte às suas atividades e para a preservação do seu capital intelectual (Chouaieb, Zaddem, \& Akremi, 2012 ; Menezes, 2006).

A transferência de conhecimento é a transmissão e a absorção de um saber a um receptor. No entanto, os métodos de transferência de conhecimento devem ser compatíveis com a cultura organizacional, pois a mera disponibilização do conhecimento não é garante seu uso (Davenport \& Prusak, 2003).

Na MountainBaja, algumas estratégias informais para a transmissão de conhecimento podem ser percebidas. Um ex-capitão da equipe, na iminência da saída do projeto, realizou as atividades do cargo acompanhadas do seu sucessor para que pudesse instruí-lo sobre a função.

"Nesse um mês de cogestão que a gente fez, fazíamos reunião de alinhamento, mostrava para ele como a gente fazia. Repassei para ele tudo que ficava comigo, bens da equipe, datashow, Gopro, uma caixa de documento que a gente tinha, expliquei para ele o que servia cada um. E fazia reuniões, perguntava o que ele estava achando, o que ele estava achando que ia pegar mais para ele. Trocava ideia mesmo" (Ex-capitão da equipe) 
41 Outro exemplo foi a de um integrante do setor de Cálculo Estrutural que, após anunciar a saída da equipe, preparou um minicurso com duração de seis horas e material didático próprio.

"Iniciativa minha, quis fazer isso, não quis sair da equipe e deixar os caras sem nada. Então achei certo o jeito de passar o conhecimento, porque eu conseguia passar e o pessoal fazendo junto, para ver se eles estavam dando conta. Mesmo assim ainda deixei o material pra eles, passei bastante tarefa pro pessoal que entrou principalmente, pra ver se eles estão dando conta do ponto atual do setor. Eu já saí da equipe, mas mesmo assim estou dando uma força para tirar dúvidas e ajudar em algumas coisas" (Membro do setor de Cálculo Estrutural)

As estratégias verificadas são, portanto, informais, já que são individuais, pontuais e esporádicas. Os participantes também relataram desinteresse sobre a tarefa de registro dos procedimentos. Falzon e Teiger (1995) dizem que os operadores só irão se interessar pela tarefa de formalizar saber se ela parecer diretamente útil para a realização da tarefa e a partir de seu ponto de vista, e não como mais uma tarefa com objetivos poucos claros.

\subsubsection{Consequências das dificuldades na retenção da experiência}

A retenção da experiência é importante porque, sem ela, perde-se conhecimento tácito, memória corporativa e investimento em treinamento (Grigg \& Zenzen, 2009). Entre os membros do BAJA, foi possível verificar que a dificuldade na retenção da experiência em alguns setores afeta o desenvolvimento do projeto.

“O pessoal fez uma suspensão no carro passado e a suspensão atuou bem. Agora as pessoas do setor são outras, aí vai fazer no carro atual, não tem uma base, não tem um projeto detalhado de como foi feito, tem que começar o projeto todo do zero. Então, todo o trabalho que uma pessoa já teve não foi passado pra frente, o que ela aprendeu" (Membro do setor de Suspensão)

“É a primeira vez que estou responsável por fazer do zero o sistema todo, pois antes havia outro rapaz que era do Baja e já tinha mais tempo e ele que pegou e fez. Agora a gente está implementando pro novo carro, pois do carro antigo foi ele que fez. Então acho que a parte mais difícil será essa" (Membro do setor de Direção)

Sem estratégias eficazes para criar e reter o conhecimento, não se tem uma abordagem de conhecimento sustentável (Evans, 2002), prejudicando o desenvolvimento do projeto, ocasionando atrasos, promovendo disparidade na experiência dos setores e desperdiçando os saberes adquiridos.

\subsubsection{Consequências : tempo reduzido para o piloto}

Na ponta do processo está o piloto, que só pode exercer sua função após a conclusão do carro. Inserido numa equipe com alta rotatividade, que não possui registros formais e não desenvolve práticas para retenção do conhecimento, os atrasos na entrega dos serviços são constantes em todos os setores e, consequentemente, o tempo de prática do piloto é reduzido. A escolha de quem irá pilotar o carro é feita pela própria equipe e tem, como critério mínimo, justamente o tempo de habilitação : é necessário ter, pelo menos, um ano de carteira com classificação B (para veículo de passeio).

Entre as avaliações da competição, o enduro tem o destaque por ser uma prova de regularidade realizada num percurso de estrada e que tem duração de quatro horas. Durante esse período, o piloto é submetido à exigência de grande esforço e resistência 
física para o controle do veículo (Silva, Plentz, Sala, \& Merino, 2013). Assim, para se alcançar experiência nessa função, deve-se conhecer o carro e a pista, praticar a direção no veículo e vivenciar, ao máximo possível, situações similares às da competição. Os próprios pilotos reconhecem essa necessidade, como pode ser observado na verbalização abaixo.

"Vou passar por um obstáculo, mas já passei por um parecido com este e se eu fizer isso vai ser melhor. Então pela experiência de pilotar e do lugar que ele está pilotando, da fórmula, e da avaliação de coisa que ele já fez, de lugar que ele já pilotou, de pista, aí o cara começa a ter experiência" (Piloto da equipe)

Gilbert (2001) diz que não há um estado normal no momento da atividade, em que tudo está sob controle, principalmente devido ao cumprimento de normas ; e, sim, que existe um constante trabalho de regulações frente às disfunções. Para o piloto, presente em um contexto onde o veículo é constantemente testado em situações adversas, vários tipos de regulações são desenvolvidas. Um dos pilotos se considerou novato em relação aos pilotos de outras equipes, justificando a sua autoclassificação com a pouca experiência de pilotagem, consequente da ausência do lastro de conhecimento na equipe.

“Tem piloto lá que já pilota há anos, já tem dois, três anos de equipe, sempre testando o carro, treinando, fica o final de semana pilotando o carro seis horas direto. 0 máximo que já pilotei o Baja direto foi três horas, mesmo assim uma vez. Agora, a gente tá tentando projetar antes do período da competição, pro carro ficar pronto a tempo e ter tempo de testar e treinar também" (Piloto da equipe)

É possível perceber, portanto, que a sobreposição de atrasos entre os setores gera uma redução do tempo de prática no veículo. Isso faz com que o piloto não tenha a oportunidade de realizar testes e, dessa forma, não possa desenvolver habilidades específicas de pilotagem nos eventos dinâmicos da competição.

\subsection{Análise da atividade como ferramenta para o mapeamento das competências : exemplo do setor de Cálculo Estrutural}

O acompanhamento das atividades dos membros da equipe contribuiu para caracterizar o perfil das competências dos participantes do BAJA. No entanto, enfatizou-se o entendimento de como os sujeitos regulam as exigências existentes na circunstância laboral, buscando desenvolver estratégias para lidar com as variabilidades e alcançar os objetivos do trabalho.

Os exemplos a seguir, do setor de Cálculo Estrutural, possibilitam situar o aporte da análise da atividade como contribuição para o mapeamento das competências (a opção pela escolha da área de Cálculo Estrutural como exemplo não foi feita ao acaso, uma vez que se trata de um setor que participa do processo de concepção do carro desde o projeto até a finalização na oficina, em um diálogo constante com os outros setores da equipe). Fragmentos das confrontações foram transcritos na íntegra e destacados no texto, em alguns momentos auxiliados por um código para distinguir os membros do setor (por exemplo, MCE2, equivale a Membro do Cálculo Estrutural n²).

51 A seguir, serão descritos quatro exemplos provenientes da análise da atividade que mostram a relação da experiência prévia dos participantes com estratégias adotadas por eles para ganhar eficiência e segurança no processo de condução do veículo. 


\subsubsection{Na ausência de protótipo, é a experiência do condutor que guia as ações}

52 O setor é composto por cinco participantes, sendo que três deles (incluindo a diretora) já participaram de uma competição e os outros dois integrados recentemente. As reuniões do grupo são realizadas uma vez por semana em encontros na universidade. 0 setor é responsável por dimensionar o chassi do carro com o menor peso possível, considerando o conforto e a segurança do piloto.

o desenho do chassi é realizado por dois integrantes mais experientes. Eles se reúnem na oficina para a metragem do carro utilizado na competição anterior e realizam o esboço em computador para, posteriormente, executarem as simulações em outro programa. Mostra-se necessário o domínio de ferramentas dos aplicativos, noções de desenho técnico e tópicos relativos à resistência dos materiais.

Durante as simulações, os integrantes realizam análises estáticas (capotamentos) e análises estruturais (colisões), definem pontos de aplicação das forças e as prováveis fontes de vibração. Para a entrada de dados no programa, características das provas que o carro é submetido são consideradas.

"Por ser um carro fora-de-estrada, tem de considerar as forças vindas do terreno,

principalmente dos componentes da suspensão e da direção" (MCE1)

Devido às questões financeiras, o projeto BAJA não possui um protótipo para ser submetido a testes em situações semelhantes às reais de competições. Para realizar simulações e buscar garantir bons resultados, os dados são interpretados pelos integrantes com experiências em competições. Esses indivíduos relatam que o formato e as condições da pista, as sensações originadas na condução do veículo e observação de situações de outros condutores os levam a uma melhor avaliação dos defeitos do veículo conduzido e, consequentemente, de seu desempenho.

“Ajuda muito pra você ter noção do que é a competição, como é a pista, porque se você faz o carro e não sabe o que ele vai sofrer, não tem como você estimar se essas forças estão certas, se a sua entrada de dados estão certas. Na competição você vê muitos carros quebrando, você vê o defeito dos outros, você consegue comparar o seu aos outros, até se o seu quebrar você consegue ver o que aconteceu" (MCE1)

Os integrantes consideram a participação da equipe nas competições uma forma de capacitar seus integrantes através da vivência e melhorar o carro para as próximas competições.

"A competição acaba sendo um teste, você consegue ver exatamente os maiores defeitos, 'Ah, então esses defeitos aconteceram porque não foi simulado bem'. Então você consegue aproveitar pra conhecer mais. Quando a gente entrou, a única simulação era de capotamento no carro e a gente já viu que há vários outros fatores que ocorrem no carro. Então este ano estamos tentando aumentar ainda mais" (MCE1)

57 Os exemplos mostram que o histórico na competição compôs o indivíduo de saberes que foram necessários na gestão da atividade, de forma a melhorar a eficiência do sistema. o domínio sobre o manejo do programa em conjunto com a percepção prática possibilitou interpretar os resultados e orientar a melhor tomada de decisão.

\subsubsection{O protótipo de bambu : experiência frustrada para melhorar as dimensões do veículo}

Na competição anterior, o setor de Ergonomia sofreu penalidades importantes em relação às dimensões do veículo, demonstrando que o carro não acomodava condutores 
de todos os portes (no momento da construção do carro o setor de Ergonomia não possuía nenhum participante, cabendo ao departamento de Cálculo Estrutural assumir estes trabalhos).

Para suprir a ausência de um carro específico para testes, a Diretora do setor de Cálculo Estrutural decidiu construir um protótipo em bambu para as regulações no chassi relativas a acomodação do piloto. $O$ intuito seria garantir resultados mais próximos da realidade e "testar o conforto do piloto", conforme verbalizado pela Diretora.

60 A construção do protótipo foi realizada na oficina da equipe. Os desenhos do chassi foram impressos com as medidas do modelo de carro da competição anterior, com as vistas necessárias, e os gabaritos feitos em folhas A2. Os bambus eram manipulados de acordo com a necessidade, sendo aparados ou arqueados e atados com fitas adesivas para se adequarem às medidas do veículo. Esse trabalho foi realizado em um único dia $\mathrm{e}$ por todos os membros do setor.

61 Os pilotos foram convidados para, juntos, redimensionassem o carro. Essa abordagem contemplaria os requisitos esperados no regulamento a partir da experiência dos próprios condutores. Os testes foram realizados durante uma semana, sempre pautados pela experiência prática dos pilotos, que verbalizavam suas percepções.

“O que estava desconfortável no carro era a perna, o pedal fica muito perto, a minha perna tinha de ficar muito dobrada. Acho que o pedal podia ficar mais longe e o encosto mais pra trás, pra ficar com a perna mais esticada. 0 braço também não ficava confortável" (Piloto da equipe)

Durante o teste, o piloto de maiores dimensões evidenciou dificuldades de entrar no protótipo que, naquele primeiro momento, possuía as mesmas dimensões do carro anterior. Os integrantes do setor, então, soltaram as fitas laterais do protótipo, aumentando o espaço interno. A parede traseira foi inclinada com a orientação do piloto, que indicava se necessitava de mais espaço ou se a ampliação da inclinação causava desconforto. Após as modificações no protótipo orientadas pelo piloto, os dados foram tratados no software e, assim, redefinidas as dimensões do novo carro.

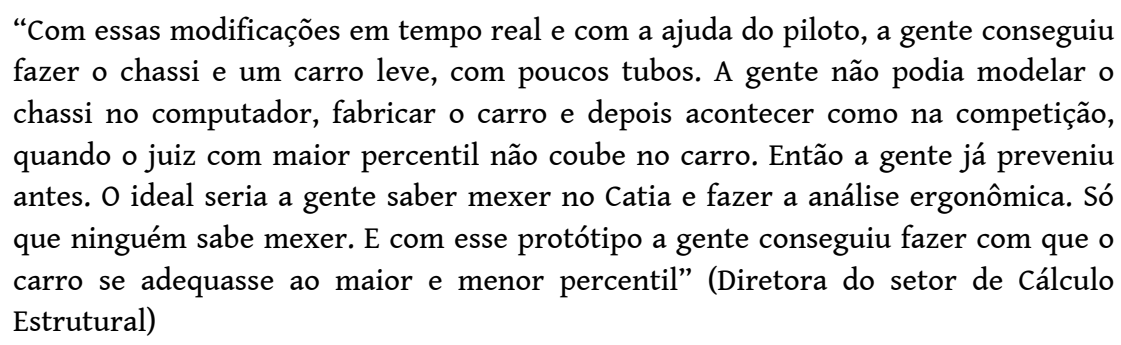

63 Este exemplo revela que os membros do setor, ao se depararem com um problema relativo a uma área desconhecida e a ausência de um protótipo apropriado para testes, elaboraram estratégias de regulação para atingir seus objetivos com um custo menor. Para reger a atividade e atuar com competência, foi necessário consultar informações em anotações, estudar o regulamento e partilhar saberes com o piloto que, com sua experiência nas competições, contribuiu para os resultados obtidos.

\subsubsection{A montagem do carro e experiência prévia em oficinas mecânicas}

64 Na montagem do carro, os participantes de todos os setores são mobilizados para as atividades ao longo de duas semanas. A prioridade é a armação do chassi e esse trabalho é orientado pelos integrantes do Cálculo Estrutural. $\mathrm{Na}$ equipe há integrantes com 
experiências em trabalhos em oficinas automotivas e outros que já participaram da montagem de carros em outras competições. Um integrante explica que a experiência neste momento é fundamental, pois é preciso conhecer bem as ferramentas, saber utilizá-las e conhecer sobre a mecânica de carros.

"Depois que desenhou o carro, simulou, viu que tá funcionando e mandou usinar as peças, ele tem que saber montar as peças no carro, saber dar manutenção, saber se está funcionando bem ou se não está. E se o carro não está funcionando bem ou não está curvando bem, ele tem que saber o que está acontecendo com o carro, onde tem que mexer. Esse conhecimento aprendi mexendo com outros carros, na prática mesmo" (Membro do setor de Direção)

Para a construção do chassi, os tubos são levados a corte, fixando-os em grampos para, com a máquina apropriada, realizar a incisão no tamanho necessário. É disposto um disco de desbaste na ferramenta de corte para a confecção do bucal que possibilita o encaixe de um tubo ao outro. Após a montagem dos tubos, é realizado um cordão de solda. Um integrante explica que é preciso cuidado com os furos e soldagens na estrutura e que se baseia no conhecimento teórico e prático já experimentado em outras situações.

"Porque se você furar a estrutura, você fragiliza ela, cria ponto que vai acumular tensão. Aí qualquer impacto ou capotamento, vai ter acúmulo de tensão e vai acontecer as falhas. E se você furar o carro inteiro ele todo vai estar fragilizado" (MCE2)

Esse histórico de prática em oficina também é importante na competição. Um piloto conta que durante uma prova de enduro, o carro apresentou dificuldades para manter uma trajetória retilínea e superar obstáculos simples. A sua experiência em mecânica automotiva o ajudou a identificar o problema, ainda pilotando, e tomar a decisão correta para solucioná-lo.

\begin{abstract}
“Como o cinto usado no Baja é de cinco pontos, você não consegue se movimentar muito, não conseguia olhar para a traseira do carro, onde eu pensava que estava o problema. Mas deduzi que ele estava com tração apenas em uma das rodas e esse era o problema. Porém, num obstáculo muito difícil de passar, o carro ficou preso e os juízes queriam me retirar da pista para que eu arrumasse o carro ali mesmo. Como sabia que o serviço era demorado e precisava de muitas ferramentas, pedi que me tirassem somente daquele obstáculo para chegar ao box. No box, com a ajuda de toda a equipe, resolvemos o problema. Voltei pra pista e dei 29 voltas, o que foi uma marca muito boa" (Piloto)
\end{abstract}

\title{
4.2.4. Testes na oficina : improvisos baseados na experiência
}

$67 \mathrm{Na}$ competição anterior, o carro apresentou dificuldades que poderiam ter sido identificadas, de acordo com os membros, se houvessem testes na oficina. Um integrante do setor de Freios conta que no torneio precedente, quando o piloto acionava o freio, o dispositivo não travava as quatro rodas. Três testes na prova foram feitos, sem sucesso, até que o integrante resolveu trocar a pastilha de freio, que é um dispositivo que exerce a resistência para diminuir a velocidade do carro. De acordo com o integrante, era um problema de fácil identificação em testes, e a experiência malsucedida pautou novas diretrizes na oficina.

"A gente percebeu que precisava de um tempo maior pra testes e pegar a intuição do que pode estar acontecendo, porque se a gente testa aqui antes, a gente já vê isso e isso ficaria na cabeça. Aí quando chegar à competição e acontecer alguma coisa parecida, já sabe o que fazer" (Membro do setor de Freios) 
a forma, alguns testes são realizados após a montagem do carro, como o realizado para verificar o impacto do capacete do piloto em caso de acidente. De acordo com o regulamento da competição, o encosto de cabeça e sua fixação à gaiola de proteção devem ser capazes de suportar uma força mínima de 890 N (200lbf) na direção normal à superfície de contato com o capacete. fosse apoiado em um poste na área externa à oficina e estabilizado com cordas. 0 encosto de cabeça foi posicionado em dois tubos transversais, seguindo o regulamento. Um integrante da equipe sentou no carro, simulando uma carga concentrada em cima do encosto. A decisão foi tomada para evitar que o carro fosse desmontado. Baseado em suas experiências com soldagem e montagem de estruturas, o integrante sabe que refazer o trabalho pode criar instabilidade na estrutura ou até mesmo perder peças sem reposição em estoque. A experiência comprovou os resultados que haviam observado na simulação em software.

"Foi uma gambiarra, mas a gente tinha de fazer o teste, não tinha outro jeito, e não tinha como desmontar a estrutura para fazer o teste e soldar de novo, senão a gente ia destruir o chassi. Então essa decisão rápida salvou" (MCE2)

teste foi realizado depois da adaptação de um reboque na dianteira do veículo. Após a soldagem do acessório, a análise no software sobre o ajuste provocou incerteza no resultado.

"Na simulação ficou um troço meio estranho perto da solda. A solda já é acúmulo de tensão, só que ficou bem fragilizada, aí a gente ficou com medo de romper e danificar a estrutura durante a competição" (MCE2)

71 O integrante do setor de Cálculo Estrutural decidiu testar içando o carro por meio de um guincho vertical da oficina. Mais uma vez, a experiência prévia com o equipamento se revelou decisivo para a execução do procedimento. Ele explicou que o processo seria suficiente pra avaliar a resistência da fixação do material e que era um teste seguro, uma vez que as rodas traseiras ficariam apoiadas no chão e o peso envolvido não seria o total do carro.

“Foi só pra ver se aguenta, porque o peso que fica ali é mínimo, não é o peso do chassi inteiro. Ele fica guinchado com duas rodas atrás apoiado, só vai guinchar a parte da frente. Então, lembrei do guincho, a gente testou e pra utilidade que a gente queria, serviu" (MCE2)

72 As distintas representações das competências necessárias à realização do trabalho colaboram para a definição de perfis de trabalhadores qualificados a ocupar esses ofícios (Guérin et al., 2001). Improvisar os testes, substituindo elementos e condições, mas pautado pelas expectativas do regulamento e experiências prévias com situações ou equipamentos similares, demonstra saberes incorporados do sujeito na circunstância de trabalho e vividos na competição.

\subsection{Os workshops realizados}

73 As observações das atividades em situação real de trabalho e a coleta de verbalizações forneceram informações sobre a percepção dos operadores em relação às competências necessárias para a função e aos níveis de similaridade em cada uma delas, o que foi fundamental para o mapeamento das competências dos indivíduos. 
74 O primeiro workshop teve como objetivo a confrontação dos dados obtidos, onde os próprios membros detectaram as competências necessárias para cada setor. Já no segundo workshop, foi possível identificar as competências e carências existentes na equipe para propor a realização do mix de similaridade.

\subsubsection{A Definição dos Níveis de Similaridade e o Mapeamento das Competências}

O material coletado nas entrevistas relativo à percepção dos componentes da equipe para cada um dos três níveis de similaridade (alto, médio e baixo) e nas análises das atividades foi apresentado em um workshop, com a participação dos diretores de cada setor. O objetivo foi realizar uma confrontação dos saberes dos indivíduos para a construção de um padrão de níveis de similaridade para cada uma das funções da equipe.

O confronto coletivo é uma forma de atividade reflexiva durante a qual um grupo de operadores, que podem ou não pertencer à mesma área de especialização, comenta a atividade de um ou mais deles. Este método permite esclarecer representações dos membros do grupo ; a construção de representações e conhecimento compartilhado de experiências individuais, possibilitando aprendizado mútuo; e avaliação coletiva dos diferentes modos de realizar a atividade e as soluções resultantes do confronto. A dinâmica da troca leva os operadores a explicar e avaliar seus próprios conhecimentos e habilidades em relação às dos outros, e desenvolver novos (Mollo \& Nascimento, 2013).

77 Num primeiro momento foram esclarecidos os objetivos do estudo, conceitos da pesquisa e como seria realizada a dinâmica proposta. Em complemento, foram relatados casos práticos da pesquisa de campo com o intuito de elucidar os principais conceitos. Assim, foi apresentado um conjunto de dados coletados nas entrevistas e solicitado aos participantes a avaliação para a construção do quadro de referência dos níveis de similaridade para a equipe.

Os participantes se colocaram a avaliar as definições dos níveis de similaridade de todos os setores e a atuação de membros mais experientes na construção do quadro se mostrou essencial por estarem imersos no contexto prático. Certos domínios considerados importantes pelos experientes poderiam passar despercebidos pelos demais integrantes ou uma pessoa de fora do projeto. Por exemplo, o tempo de participação na equipe não foi considerado pelos diretores como garantia de níveis mais altos de similaridade. Essa afirmação vai de encontro ao entendimento de que muitos anos participando da equipe se traduz em altos níveis de similaridade.

“Tem gente que corre atrás, quer aprender o tempo todo, é mais participativo na

oficina e assim vai ficando mais experiente. A mesma coisa vale se o cara está há um

tempão na equipe e não busca conhecimento" (Diretor da equipe)

Outro diretor destacou que ter boa capacidade de apresentação de pôsteres de projetos na competição e o conhecimento integral do regulamento da competição são atribuições determinantes para identificar experiência em todos os departamentos.

Além desses dados, os participantes realizaram modificações em todos os setores do projeto. Por exemplo, no setor de Design e Acabamento, a capacidade de preparar os moldes de laminação citada como característica de média similaridade foi, ao final, ajustada à de baixa similaridade, bem como foi também inserida a esse nível a capacidade de identificar peças que o departamento necessita confeccionar. No setor de 
Eletrônica, sete itens foram incluídos à alta similaridade, dentre eles o uso de alguns softwares, manufatura de circuitos impressos, habilidade para montar chicote elétrico e também incluso um tópico relacionado ao diretor do setor, que deve ser capaz de treinar e gerenciar os demais membros. Em Suspensão e Direção foi estabelecido à baixa similaridade o domínio de ferramentas básicas. Em Materiais e Suprimentos foram acrescidos à seção de alta similaridade tópicos relativos às habilidades na competição como entendimento de demandas (alimentação, transporte e local para ficar), elaboração de componentes para competição (peças, ferramentas) bem como o controle das ferramentas.

81 A competência envolve um saber agir responsável e reconhecido que implica mobilizar, integrar, transferir conhecimentos, recursos e habilidades (Fleury \& Fleury, 2001) e o seu mapeamento orienta as estratégias que visam atingir os objetivos da organização, como : contratação de pessoal que agregue conhecimento ao já existente; adoção de alianças formais com parceiros que detêm o conhecimento necessário à empresa; elaboração de planos de capacitação para todo o quadro empresarial, entre outras. Para tanto, é necessário fazer o levantamento e registro das habilidades e competências requeridas para cada atividade (Strauhs et al., 2012).

82 A elaboração da tabela de Níveis de Similaridade neste workshop revelou os diferentes tipos de conhecimentos necessários à realização da atividade em cada setor. A Tabela 1 demonstra, a título de exemplo, os resultados obtidos no setor de Cálculo Estrutural.

Tabela de níveis de similaridade para o setor de Cálculo Estrutural (elaborada pelos autores)

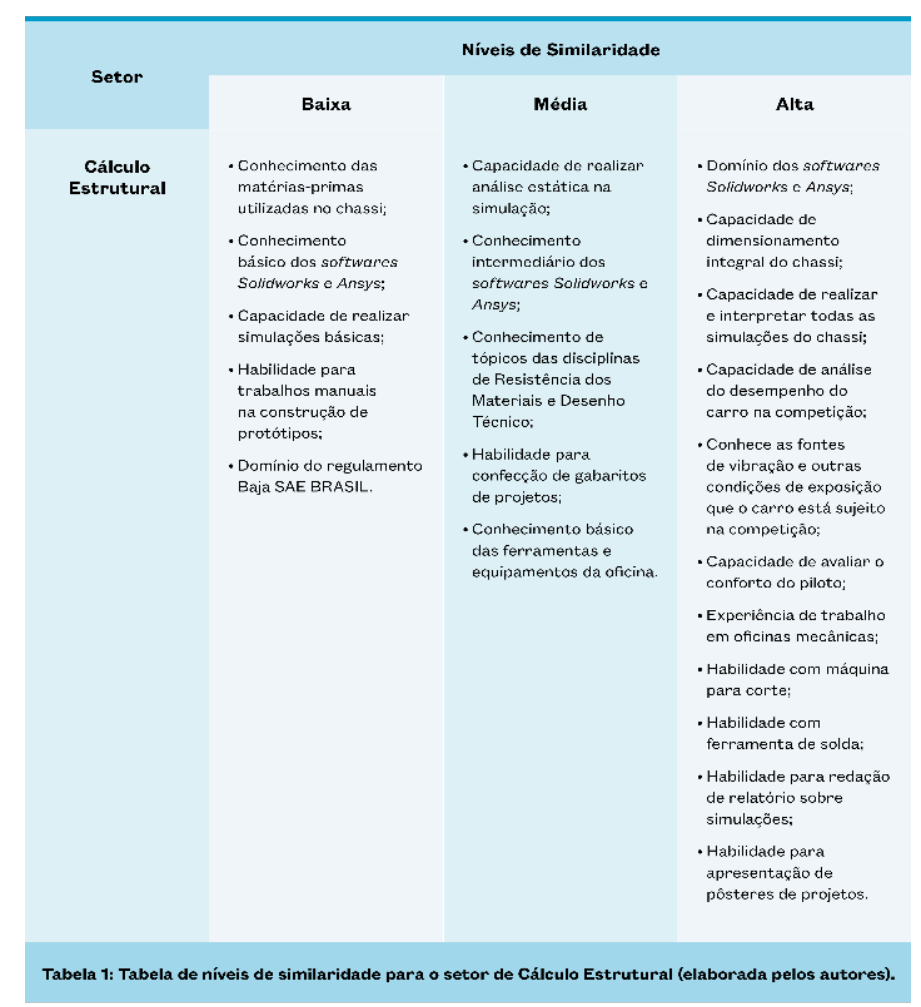

TABELA 1. Tabela de níveis de similaridade para o setor de Cálculo Estrutural (elaborada pelos autores)

83 Após definirem o quadro conceitual dos níveis de similaridade, os participantes avaliaram os setores atuais da equipe identificando os conhecimentos existentes e classificaram os integrantes como sendo de baixa, média ou alta similaridade. Assim, foi 
produzida uma tabela que mostra a configuração de cada um dos setores do projeto, que pode ser vista na Tabela 2.

Configuração atual dos setores pelos níveis de similaridade

\begin{tabular}{|c|c|c|c|}
\hline \multirow{2}{*}{ Setor } & \multicolumn{3}{|c|}{ Nivel de Similaridade } \\
\hline & Baixa & Média & Alta \\
\hline Suspensão / Direção & 0 & 3 & 0 \\
\hline Elétrica & 2 & 2 & 2 \\
\hline Capitão & 0 & 1 & 0 \\
\hline Transmissão & 0 & 3 & 0 \\
\hline Cálculo Estrutural & 1 & 1 & 1 \\
\hline Freio & 0 & 2 & 1 \\
\hline Materiais / Suprimentos & 0 & 1 & 0 \\
\hline Design / Acabamentos & 0 & 3 & 1 \\
\hline Ergonomia & 0 & 1 & 0 \\
\hline Gestão de Projectos & 0 & 1 & 0 \\
\hline Gestão de Pessoas & 1 & 0 & 0 \\
\hline Administrativo / Financeiro & 0 & 1 & 0 \\
\hline Piloto & 0 & 2 & 1 \\
\hline Marketing / Patrocinio & 0 & 0 & 1 \\
\hline
\end{tabular}

TABELA 2. Configuração atual dos setores pelos níveis de similaridade

\subsubsection{Em busca do Mix de Similaridade correto} conhecendo a dinâmica do carro nos diversos testes em que é submetido. Entretanto, se o condutor possuir mais participações em competições, terá experimentado mais conjunturas e conseguirá sentir o carro em situações onde terá de tomar decisões rápidas. Se junto a essa experiência o sujeito também possuir conhecimentos em mecânica veicular, suspensão e direção automotiva, o indivíduo será considerado de alta similaridade. 
87 Saber utilizar o software Catia confere ao membro do setor de Ergonomia média similaridade para o cumprimento do regulamento. No entanto, se o integrante possuir experiência com a adaptação de chassi em diferentes percentis e participação na competição, ele será considerado de alta similaridade, pois terá observado o sistema homem-máquina e contribuirá para análises mais precisas sobre a concepção do carro.

No setor de Cálculo Estrutural, assim que o praticante passa do processo trainee, esperase que ele já tenha conhecimento do regulamento, bem como de softwares de desenho e simulação necessários para o dimensionamento do chassi. Também é importante que conheça as matérias-primas utilizadas na concepção da estrutura para a busca por fornecedores. Este integrante é considerado de baixa similaridade, pois conseguirá realizar análises simples de simulação. Quando este sujeito já consegue interpretar resultados mais elaborados, dominando o conteúdo de disciplinas de resistência dos materiais e desenho técnico, além de possuir habilidades para confecção de gabaritos para projetos, ele é considerado de média similaridade. A participação em competição confere ao integrante patamar de experiente, haja vista que é possível perceber fontes de vibração e outras condições de exposição que o carro está sujeito durante as provas, além de habilidades para análises estruturais. A experiência prévia do integrante com oficinas mecânicas, ferramentas e equipamentos, e o funcionamento de carros, também atribui a esse indivíduo experiência necessária para a montagem do veículo e soluções para conflitos na competição. Essas características lhe conferem atributos de alta similaridade para o setor.

A partir da definição dos critérios das competências, o mix de similaridade foi proposto para os setores. Uma equipe somente com pessoas de alta similaridade seria a solução para qualquer projeto, mas isso nunca é possível, neste caso ainda menos por se tratar de um projeto universitário, com estudantes que desempenham diversas atividades acadêmicas obrigatórias para se graduar em seus cursos. Dessa forma, tornou-se necessário pensar numa composição efetiva para cada um dos setores, que permitisse a construção de um projeto final eficaz.

90 Uma síntese das necessidades dos setores destacadas no segundo workshop é demonstrada na Tabela 3. Foram expressos no quadro os níveis de similaridade atuais e aqueles que, por meio do mix de similaridade, devem ser pretendidos na captação de novos membros. Assim, para cada um dos setores do projeto BAJA, foi possível identificar a configuração atual e quantos indivíduos de baixa, média ou alta similaridade eram necessários para compor a equipe de forma a constituir uma equipe eficiente na construção de um novo veículo. 
Configuração com o mix de similaridade

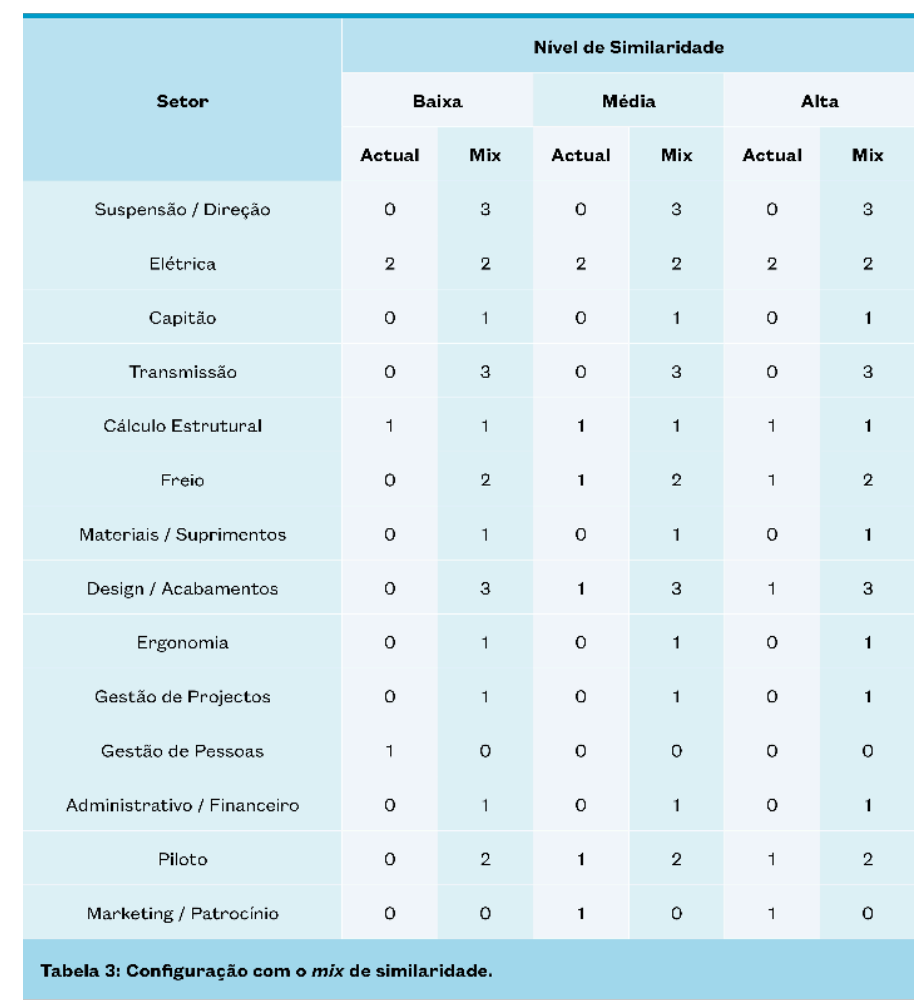

TABELA 3. Configuração com o mix de similaridade

91 Dessa forma, por meio do método desenvolvido, foi proposto ao projeto que, nas próximas seleções de membros, buscassem admitir estudantes com perfis que atendam a alta similaridade para o setor de Suspensão e Direção ; três integrantes de baixa e um de média similaridade para o setor de Materiais e Suprimentos; um integrante de média similaridade para o setor de Ergonomia; dois integrantes de média similaridade e um de alta para o setor de Gestão de Pessoas ; e três integrantes de média similaridade para o setor de Marketing e Patrocínio.

\section{Considerações finais}

Essa pesquisa demonstrou a necessidade de uma gestão do conhecimento tácito na equipe MountainBaja, construída com base na compreensão do trabalho por conceitos e ferramentas da Ergonomia da Atividade, bem como no desenvolvimento de workshops para o mapeamento das competências dos indivíduos e setores do projeto BAJA.

O mapeamento das competências baseado na análise da atividade foi aplicado para qualificar a experiência e os envolvidos na atividade tiveram a capacidade de discriminar especificidades da função e identificar as carências em termos de competências no projeto. A definição de níveis de similaridade pela própria equipe se apresentou como ponto de partida importante para planejamentos relativos à gestão do conhecimento tácito, uma vez que, a partir disso, entendem-se as necessidades reais relacionadas às competências desejadas para a realização daquela atividade.

Foi possível perceber que, compartilhando experiências e buscando encontrar as verdadeiras necessidades dos setores em termos de competências, evita-se que novos 
membros gastem tempo e recursos em tentativas infrutíferas anteriormente experimentadas. Ao mesmo tempo, a participação dos indivíduos na pesquisa mostrou que, apesar das dificuldades de manutenção do conhecimento na equipe devido à alta rotatividade dos seus membros, foram justamente aqueles exemplos em que a experiência de situações anteriores foi constatada, e pôde ser replicada numa situação nova, que favoreceram um melhor desempenho do projeto.

Esse artigo é um dos primeiros a propor uma relação entre os conceitos de "competência" de campos convergentes, mas não necessariamente similares, como a Gestão do Conhecimento Tácito e a Ergonomia. Essa proposta pode trazer contribuições teóricas a ambas as áreas, bem como contribuições práticas para organizações que convivam com alta rotatividade e necessitem encontrar maneiras de reter o conhecimento no seu interior. Assim, é possível vislumbrar pesquisas semelhantes a essas em organizações de naturezas diferentes, sejam elas ligadas à indústria, serviços ou ao mercado informal.

\section{BIBLIOGRAFIA}

Balcão, Y. F. (1965). Organograma : representação gráfica da estrutura. Revista de Administração de Empresas, 5(17), 107-125. https://doi.org/10.1590/S0034-75901965000400003

Choo, C. (2003). A organização do conhecimento : como as organizações usam a informação para criar significado, construir conhecimento e tomar decisões. São Paulo : Editora Senac São Paulo.

Chouaieb, A., Zaddem, F., \& Akremi, A. E. (2012). La mémoire organisationnelle et la dynamique de pouvoir dans l'entreprise. Revue internationale sur le travail et la société, 10(1), 24-50.

Collins, H. (2010). Tacit and explicit knowledge. Chicago : The University of Chicago Press.

Davenport, T., \& Prusak, L. (2003). Conhecimento empresarial : como as organizações gerenciam o seu capital intelectual. Rio de Janeiro : Elsevier.

Delgoulet, C. (2015). Novato : uma categoria homogénea ? Laboreal, 11(2), 99-103. https:// journals.openedition.org/laboreal/3840

Delgoulet, C., \& Vidal-Gomel, C. (2013). Le développement des compétences : une condition pour la construction de la santé et de la performance au travail. In P. Falzon (Dir.), Ergonomie Constructive (pp. 19-32). Paris : PUF.

Departamento Intersindical de Estatística e estudos Socioeconômicos (DIEESE) (2011). Rotatividade e flexibilidade no mercado de trabalho. São Paulo : DIEESE. https://bit.ly/3eRSoeC

Dreyfus, H. (2001/ 2009). On the Internet. London and New York : Routledge.

Dreyfus, H., \& Dreyfus, S. (2012). Expertise intuitiva : para além do pensamento analítico. Belo Horizonte : Fabrefactum.

Evans, C. (2002). Developing and Retaining Organisational Knowledge. Roffey Park Institute. https:// bit.ly/3alAdeX

Falzon, P. (2007). Ergonomia. São Paulo : Blucher. 
Falzon, P. (2016). Ergonomia Construtiva. São Paulo : Blucher.

Falzon, P., \& Mollo, V. (2009). Para uma ergonomia construtiva : as condições para um trabalho capacitante. Laboreal, 5(1), 61-69. https://journals.openedition.org/laboreal/10429

Falzon, P., \& Teiger, C. (1995). Construire l'activité. Performances Humaines et Techniques, hors-série, 34-40.

Faurie, I., Planché, F., Deltor, S., Ricaud, C., Grau, A., \& Guy, C. (2013). Comprender mejor la Transferencia de Conocimientos en Salud y Seguridad en el Trabajo : Propuestas para una tipología de guías de prevención. Laboreal, 9(2), 52-62. https://journals.openedition.org/laboreal/ 5750

Ferreira, E. G., \& Caporalli Filho, A. (2013, setembro). Influências do projeto Baja SAE no ensino da engenharia e no desenvolvimento do aluno. Comunicação apresentada no XLI Congresso Brasileiro de Educação em Engenharia. Gramado, Brasil. https://bit.ly/3564Ym4

Ferreira, M., \& Freire, O. (2001). Carga de trabalho e rotatividade na função de frentista. Revista de Administração Contemporânea, 5(2), 175-200. https://doi.org/10.1590/S1415-65552001000200009

Fleury, M., \& Fleury, A. (2001). Construindo o Conceito de Competência. RAC, Edição Especial, 183-196. https://bit.ly/3aEODpv

Fórum de Pró-Reitores de Extensão das Universidades Públicas Brasileiras (2001). Plano Nacional de Extensão Universitária. Ilhéus : Editus.

Fórum de Pró-Reitores de Extensão das Universidades Públicas Brasileiras. (2007) Extensão Universitária : Organização e Sistematização. Belo Horizonte : COOPMED.

Frufrek, G., \& Pansanato, L. (2017). Rotatividade de Pessoal : Pesquisa com Profissionais de Empresas Brasileiras de Desenvolvimento de Software. Revista Brasileira de Sistemas de Informação, 10(2), 05-29. http://www.seer.unirio.br/index.php/isys/article/view/6142

Gil, A. (2008). Métodos e Técnicas de Pesquisa Social. São Paulo : Atlas.

Gilbert, C. (2001). Retours d'expérience : le poids des contraintes. Annales des mines, 4, 9-24. https://bit.ly/2WOETRm

Granovsky, P., \& Poy, M. (2012). Construcción de conocimientos y apropiación de nuevas técnicas de diagnóstico de fallas en operadores de talleres de reparación de automóviles. Laboreal, 8(2), 74-87. https://journals.openedition.org/laboreal/6706

Grigg, N. S., \& Zenzen, M. K. (2009). The Water Workforce : Recruiting \& Retaining High-Performance Employees. Denver : American Water Works Association.

Guérin, F., Laville, A., Daniellou, F., Duraffourg, J., \& Kerguelen, A. (2001). Compreender o trabalho para transformá-lo : a prática da ergonomia. São Paulo : Edgard Blücher ; Fundação Vanzolini.

Lima, S. (2018). Estudo da gestão do conhecimento em uma equipe de desenvolvimento de veículos off-road para competições (Trabalho de Graduação). Universidade Federal de Juiz de Fora, Juiz de Fora, Brasil. https://bit.ly/357DigG

Linares, M., Sartor, F., Oliveira, D., Cabral, A., \& Assis, A. (2013, maio). Planejamento, Desenvolvimento, Fabricação e Montagem de um Protótipo Veicular fora de Estrada. Comunicação apresentada no Congresso Brasileiro de Engenharia de Fabricação. Penedo, Itatiaia, Brasil. https://bit.ly/38gMSxQ

Lüdke, M., \& André, M. (1986). A pesquisa em educação : abordagens qualitativas. São Paulo : EPU. 
Mata, C., Oliveira, F. G., \& Barros, V. (2017). Experiência, Atividade, Corpo : Reflexões na confluência da Psicossociologia do Trabalho e Ergologia. Psicologia em Revista, 23(1), 361-373. http://dx.doi.org/10.5752/P.1678-9563.2017v23n1p361-373

Menezes, E. M. (2006). Estruturação da memória organizacional de uma instituição em iminência de evasão de especialistas : um estudo de caso na COHAB (Dissertação de Mestrado). Programa de PósGraduação em Gestão do Conhecimento e Tecnologia da Informação, Universidade Católica de Brasília, Brasília, Brasil.

Mollo, V., \& Nascimento, A. (2013). Pratiques rélexives et développement des individus, des collectifs et des organisations. In P. Falzon (Dir.), Ergonomie constructive (pp. 207-222). Paris : PUF.

Ress, A., Moraes, R., \& Nakano, D. (2010, outubro). O uso da gestão de conhecimento como fator de moderação do impacto da alta rotatividade da equipe de TI no desempenho dos projetos. Comunicação apresentada no XX Encontro Nacional de Engenharia de Produção, São Carlos, Brasil. https:// bit.ly/35mPzwH

Ribeiro, I. (2015). Estudo sobre o gerenciamento de projeto de desenvolvimento de um veículo baja para competições (Trabalho de Graduação). Faculdade de Engenharia do Campus de Guaratinguetá, Universidade Estadual Paulista, Guaratinguetá, Brasil. https://bit.ly/373cUEJ

Ribeiro, R. (2013). Tacit knowledge management. Phenomenology and the cognitive sciences, 12, 337-366. http://dx.doi.org/10.1007/s11097-011-9251-x

Rocha, R. (2017). Atividade coletiva na redução da carga de trabalho : uma articulação entre regulações quentes e frias. Revista Brasileira de Saúde Ocupacional, 42(5), 1-13. https://doi.org/ $10.1590 / 2317-6369000005316$

Rocha, R., Mollo, V., \& Daniellou, F. (2019). Contributions and conditions of structured debates on work on safety construction. Safety Science, 113, 192-199. https://doi.org/10.1016/j.ssci.

2018.11.030

Runte, G. (2011). Gestão do Conhecimento : Os desafios da implantação de um modelo integrado - o caso ANS (Dissertação de Mestrado). Fundação Getúlio Vargas, Rio de Janeiro, Brasil. https://bit.ly/ $3 \mathrm{eXxLOg}$

SAE Brasil (2019). Baja SAE BRASIL. Retrieved October 9, 2019, from https://bit.ly/204gZla

Schultz, G. (2016). Introdução à gestão de organizações. Porto Alegre : Editora da UFRGS.

Silva, D., Plentz, B., Sala, S., \& Merino, E. (2013). A Ergonomia na Identificação dos Aspectos Dimensionais Críticos : O Estudo Antropométrico de um Carro de Competição BAJA SAE. Human Factors Design, 2(3), 3-19. http://www.revistas.udesc.br/index.php/hfd/article/view/5679

Silva, R., Cappellozza, A., \& Costa, L. (2014). O impacto do Suporte Organizacional e do Comprometimento Afetivo sobre a Rotatividade. Revista de Administração IMED, 4(3), 314-329. https://doi.org/10.18256/2237-7956/raimed.v4n3p314-329

Soares, A., \& Andrade, G. (2005). Gestão por competências : uma questão de sobrevivência em um ambiente empresarial incerto. Comunicação apresentada no II Simpósio de Excelência em Gestão e Tecnologia - SEGET, Resende, Brasil. https://bit.ly/372eVkC

Strauhs, F., Pietrovski, E., Santos, G., Carvalho, H., Pimenta, R., \& Penteado, R. (2012). Gestão do conhecimento nas organizações. Curitiba : Aymará Educação.

Stroobants, M. (2006). Competência. Laboreal, 2(2), 78-79. https://journals.openedition.org/ laboreal/13416 
Sznelwar, L. (2009). O trabalho sob um olhar sustentável - desafios para os serviços de saúde pública : Estudo de caso do Programa Saúde da Família em São Paulo, Brasil. Laboreal, 5(1), 38-52. https://journals.openedition.org/laboreal/10345

Takeuchi, H., \& Nonaka, I. (2008). Criação e dialética do conhecimento. In H. Takeuchi, \& I. Nonaka (Eds.), Gestão do conhecimento (pp. 17-38). Porto Alegre : Bookman.

Tonet, H., \& Paz, M. (2006). Um modelo para o compartilhamento de conhecimento no trabalho. Revista de Administração Contemporânea, 10(2), 75-94. https://doi.org/10.1590/

S1415-65552006000200005

Triviños, A. (1987). Introdução à Pesquisa em Ciências Sociais : A Pesquisa Qualitativa em Educação. São Paulo: Atlas.

\section{RESUMOS}

Este estudo teve por objetivo mapear o conhecimento tácito de integrantes de uma equipe universitária de construção de um veículo fora de estrada, conhecido como BAJA, para identificar as carências de uma equipe com grande rotatividade entre seus membros e propor alternativas para a retenção do conhecimento. Buscou-se conhecer a atividade de trabalho dos membros por meio de observações da atividade real e entrevistas. Em seguida, foram realizados workshops com o intuito de efetuar um mapeamento da experiência dos seus participantes e de definir as carências em termos de competência, em cada um dos setores do projeto. Os resultados mostram que a compreensão e o mapeamento do conhecimento tácito permitiram identificar as principais necessidades de qualificação no projeto e criar perspectivas de contratação específicas. Ao mesmo tempo, esta pesquisa mostra a necessidade de articulação entre os conceitos de competência oriundos da Ergonomia da Atividade e da Gestão do Conhecimento Tácito.

Este estudio tuvo como objetivo mapear el conocimiento tácito de los miembros de un equipo universitario de construcción de un vehículo todoterreno, conocido como BAJA, para identificar las necesidades de un equipo con alta rotación entre sus miembros y proponer alternativas para La retención del conocimiento. Buscamos conocer la actividad laboral de los miembros a través de observaciones de la actividad real y entrevistas. Luego se realizaron talleres para mapear la experiencia de sus participantes y definir la escasez de habilidades en cada uno de los sectores del proyecto. Los resultados muestran que la comprensión y el mapeo del conocimiento tácito permitieron identificar las principales necesidades de calificación en el proyecto y crear perspectivas específicas de contratación. Al mismo tiempo, esta investigación muestra la necesidad de articulación entre los conceptos de competencia de Activity Ergonomics y Tacit Knowledge Management.

Cette étude visait à cartographier les connaissances tacites des membres d'une équipe universitaire construisant un véhicule tout-terrain, connu sous le nom de BAJA, pour identifier les besoins d'une équipe à fort roulement parmi ses membres, et donc proposer des alternatives pour la rétention des connaissances. Nous avons cherché à connaître l'activité de travail des membres, à travers des observations de l'activité réelle et des entretiens. Des ateliers ont ensuite été menés pour cartographier l'expérience de ses participants et définir les pénuries de compétences dans chacun des secteurs du projet. Les résultats montrent que la compréhension et la cartographie des connaissances tacites nous ont permis d'identifier les principaux besoins de qualification dans le projet et créer des perspectives d'embauche spécifiques. Dans le même temps, cette recherche montre la nécessité d'une articulation entre les concepts de compétence de l'ergonomie d'activité et de la gestion des connaissances tacites. 
This study aimed to map the tacit knowledge of members of a university team responsible for building an off-road vehicle, known as BAJA, to identify the needs of a team with high turnover among its members and to propose alternatives for the knowledge retention. We sought to know the members work activity through observations of the actual activity and interviews. Workshops were then conducted to map the experience of its participants and to define the skills shortages in each of the project sectors. The results show that understanding and mapping tacit knowledge made it possible to identify the main qualification needs in the project and create specific hiring perspectives. At the same time, this research shows the need for articulation between the concepts of competence from Activity Ergonomics and Tacit Knowledge Management.

\section{ÍNDICE}

Palavras-chave: análise da atividade, BAJA, ergonomia, gestão do conhecimento tácito, mix de similaridade

Palabras claves: análisis de actividad, BAJA, ergonomía, gestión tácita del conocimiento, mezcla de similitud

Mots-clés: analyse d'activité, BAJA, ergonomie, gestion des connaissances tacites, mélange de similitude

Keywords: activity analysis, BAJA, ergonomics, tacit knowledge management, similarity mix

\section{AUTORES}

\section{RODRIGO AUGUSTO DOS SANTOS}

Universidade Federal de Itajubá - Núcleo de Estudo e Pesquisa Sobre trabalho Humano (NEPETH). Rua Irmã Ivone Drumond, 200, Distrito Industrial II. 35903-087 Itabira, MG.

correiodorodrigo@live.com

\section{RAONI ROCHA}

Universidade Federal de Itajubá - Núcleo de Estudo e Pesquisa Sobre trabalho Humano (NEPETH). Rua Irmã Ivone Drumond, 200, Distrito Industrial II. 35903-087 Itabira, MG.

raoni@unifei.edu.br 